\title{
Concepção da Curricularização da Extensão no Bacharelado em Sistemas de Informação: Relato de Experiência do IFAL Campus Maceió
}

\author{
Mônica Ximenes Carneiro da Cunha ${ }^{1}$, Marcílio Ferreira de Souza Júnior ${ }^{2}$ \\ ${ }^{1}$ CINFO - Campus Maceió - Instituto Federal de Alagoas (IFAL) \\ Maceió - AL - Brasil \\ ${ }^{2}$ CODAI - Universidade Federal Rural de Pernambuco (UFRPE) \\ São Lourenço da Mata - PE - Brasil \\ marcilio.souzajr@ufrpe.br, monica@ifal.edu.br
}

\begin{abstract}
The National Education Plan (2014-2024) establishes the adequacy of the undergraduate courses pedagogical projects to include extension activities in their curricula, ensuring at least $10 \%$ of the total credits. This article aims to present a report on the design of the first extension curricular proposal at IFAL, contemplated in the Bachelor of Information Systems since 2018. The proposal consisted of offering three mandatory subjects (integrative projects and social and assistive technologies) and participation in other institutionalized extension activities (programs, projects, courses, technological extension services and volunteering).
\end{abstract}

Resumo. O Plano Nacional de Educação 2014-2024 estabelece a adequação dos projetos pedagógicos dos cursos de graduação para inserção de atividades de extensão nos seus currículos, assegurando no mínimo $10 \%$ do total de créditos, o que foi denominado de "curricularização da extensão". Este artigo tem como objetivo apresentar um relato sobre a concepção da primeira proposta de curricularização da extensão em um curso do IFAL, contemplada no Bacharelado em Sistemas de Informação desde o semestre 2018-1. A proposta consistiu na oferta de três disciplinas obrigatórias (duas de projetos integradores e uma de tecnologias sociais e assistivas) e participações em outras atividades extensionistas institucionais (programas, projetos, cursos, serviços de extensão tecnológica e voluntariado).

\section{Apresentação}

O Plano Nacional de Educação (PNE) 2014-2024 estabelece a adequação dos projetos pedagógicos dos cursos (PPC) de graduação para inserção de atividades de extensão nos seus currículos, assegurando no mínimo $10 \%$ do total de créditos curriculares como meta. Esse processo institucional de adequação dos PPCs para inserção do percentual exigido tem sido denominado em algumas instituições de "creditação curricular" e, em outras, de “curricularização" [Frutuoso 2020; Mello, Almeida-Neto e Petrillo 2020]. A referida meta visa garantir ao discente um aprofundamento em um campo do saber, agregado a uma formação social e humanística no atendimento de demandas comunitárias [Steigleder, Zucchetti e Martins 2019; Serva 2020]. 
Imperatore, Pedde e Imperatore (2015) reconheceram a extensão como função acadêmica integrada ao currículo pautando-se no conceito defendido pelo Fórum de PróReitores de Extensão, que foi definida como um "processo acadêmico definido e efetivado em função das demandas sociais, políticas, econômicas e culturais da sociedade e da proposta pedagógica dos cursos, coerente com as políticas públicas e, indispensável à formação cidadã" [Steigleder, Zucchetti e Martins 2019].

No Instituto Federal de Alagoas (IFAL) Campus Maceió, as adequações visando a curricularização da extensão iniciaram com a reformulação do Bacharelado em Sistemas de Informação (BSI) em 2017 tomando por base as Diretrizes Curriculares Nacionais e os Currículos de Referência da Sociedade Brasileira de Computação (SBC).

Nesta vertente, no que tange a extensão, a concepção da proposta pedagógica do BSI/IFAL atendeu às exigências da curricularização ao propiciar aos alunos a oportunidade de aplicar os conhecimentos adquiridos nos componentes curriculares através de ações e atividades institucionalizadas visando solucionar demandas do entorno do ambiente acadêmico.

Este artigo tem como objetivo apresentar um relato sobre a concepção da primeira proposta de curricularização da extensão em um curso do IFAL, incluída no novo PPC do Bacharelado em Sistemas de Informação, iniciado no semestre 2018-1 e com previsão de término para 2022. O restante do artigo está organizado da seguinte forma: na seção 2 são apresentados os resultados após a reorganização curricular do BSI/IFAL e na seção 3 são descritas as principais dificuldades encontradas durante o delineamento da proposta, culminando com algumas recomendações.

\section{Resultados da reorganização curricular contemplando atividades de extensão}

A carga horária do BSI/IFAL totaliza 3166,66 horas, obedecendo, portanto, a Resolução $\mathrm{CNE} / \mathrm{CES} \mathrm{n}^{\circ}$ 02/2007, que estabelece a carga horária mínima de 3000 horas para o Bacharelado em Sistemas de Informação. Como a hora-aula no IFAL é dimensionada para 50 minutos, a carga horária total do curso consiste em 3800 horas-aula.

A carga horária para curricularização da extensão correspondeu a $10 \%$ do total, ou seja, 380 horas-aula, compreendendo três componentes curriculares obrigatórios (totalizando 160 horas-aula) e outras atividades extensionistas diversas, como participações em programas, projetos, cursos, serviços tecnológicos e voluntariado (totalizando 220 horas-aula), conforme apresentado no quadro 1.

Quadro 1. Estratégias de curricularização adotadas na concepção do curso

\begin{tabular}{|l|l|c|}
\hline $\begin{array}{c}\text { ESTRATÉGIAS DE } \\
\text { CURRICULARIZAÇÃO }\end{array}$ & AÇÕES & $\begin{array}{c}\text { CARGA } \\
\text { HORÁRIA }\end{array}$ \\
\hline \multirow{3}{*}{$\begin{array}{l}\text { Componentes curriculares } \\
\text { (Disciplinas) }\end{array}$} & $\begin{array}{l}\text { Oferta da disciplina Projeto Integrador (modalidade EAD) } \\
\text { no 5o período do curso }\end{array}$ & $40 \mathrm{~h}$ \\
\cline { 2 - 4 } & $\begin{array}{l}\text { Oferta da disciplina Projeto Integrador em SI no 6o } \\
\text { período do curso }\end{array}$ & $80 \mathrm{~h}$ \\
\cline { 2 - 3 } & $\begin{array}{l}\text { Oferta da disciplina Tecnologias Sociais e Assistivas no } \\
\text { 8o período do curso }\end{array}$ & $40 \mathrm{~h}$ \\
\hline
\end{tabular}




\begin{tabular}{|c|c|c|}
\hline $\begin{array}{l}\text { Programas, projetos e } \\
\text { cursos de extensão } \\
\text { institucionais }\end{array}$ & $\begin{array}{l}\text { Atividades institucionalizadas, que podem ser financiadas } \\
\text { com bolsas da Pró-reitoria de Extensão (PROEX). }\end{array}$ & \multirow{3}{*}{$220 \mathrm{~h}$} \\
\hline $\begin{array}{l}\text { Serviços de Extensão } \\
\text { Tecnológica }\end{array}$ & $\begin{array}{l}\text { Ações voltadas a projetos cooperados com empresas } \\
\text { demandantes, através de ações de transferência de } \\
\text { tecnologia, serviços tecnológicos e propriedade intelectual }\end{array}$ & \\
\hline Voluntariado & $\begin{array}{l}\text { Ações realizadas pelos alunos, de forma voluntária, sem } \\
\text { vínculo com a instituição de ensino, mas devidamente } \\
\text { comprovada, em comunidades ou entidades externas sobre } \\
\text { temáticas sociais pertinentes ao curso. }\end{array}$ & \\
\hline
\end{tabular}

$\mathrm{Na}$ reorganização curricular, as disciplinas "Projeto Integrador" (modalidade ensino a distância) e "Projeto Integrador em Sistemas de Informação" têm ementas voltadas à aplicação dos conteúdos programáticos envolvendo todas os componentes curriculares do período na execução de um projeto interdisciplinar e aplicado para atender a comunidade. Por sua vez, a disciplina "Tecnologias Sociais e Assistivas" está voltada para concepção de projetos para promover inclusão social e para projetar novas tecnologias assistivas para os cidadãos. Todas foram delineadas sob medida para oportunizar ações de extensão, uma vez que os respectivos conteúdos programáticos e ementas têm o potencial de sensibilizar e desafiar os discentes para o desenvolvimento de soluções tecnológicas transformadoras, em atendimento às demandas sociais, por meio de produtos ou serviços inovadores.

A comissão responsável por elaborar o novo PPC do BSI/IFAL chegou até esses componentes curriculares após discussão, debates, escuta de narrativas e experiências dos docentes em relação às suas próprias ações alinhadas com o atendimento de demandas da comunidade. Os professores do BSI/IFAL já trabalham com projetos integradores, que visam promover a interdisciplinaridade entre as disciplinas do semestre letivo, desde 2007 [Cunha e Souza-Júnior 2007]; portanto, com vasta experiência com metodologias baseadas em projetos de desenvolvimento tecnológico.

Cabe ressaltar que todas as atividades relacionadas a programas, projetos, cursos, serviços de extensão tecnológica ou voluntariado são obrigatórias e precisam estar devidamente documentadas e aprovadas pelo colegiado do curso, com a execução sob supervisão de um ou mais docentes.

\section{Desafios encontrados e recomendações}

Os desafios enfrentados durante o percurso de concepção da proposta de curricularização da extensão no BSI/IFAL envolveram diversas esferas, desde o entendimento da legislação disponível à época, passando pela análise da amplitude das propostas possíveis ao contexto da instituição de ensino e ao alinhamento com a experiência dos professores que já participavam de projetos voltados para a comunidade externa, até a prospecção de tendências aventadas em 2017, que inclusive foram catalogadas posteriormente em regulamentação própria [BRASIL 2018], norteando a curricularização da extensão para as instituições de ensino.

Um desafio da extensão curricularizada é buscar garantir a dialogicidade das propostas voltadas para problemas sociais, refletindo os resultados alcançados das ações para dentro dos espaços de salas de aula e laboratórios de pesquisa, o que efetivamente 
possibilitará uma troca de vivências extramuros inerentes à extensão. Somente assim a curricularização da extensão contribuirá com a formação integral do estudante, estimulando sua construção como cidadão crítico e capaz de utilizar os seus conhecimentos em prol da resolução dos problemas da sociedade.

A concepção curricular aqui relatada envolveu as etapas de atendimento à regulamentação e ao processo de atualização e reorganização do PPC. A primeira turma a cursar as atividades extensionistas do currículo foi o 5o período no semestre 2020-1 a partir da matrícula na disciplina Projeto Integrador em SI (ofertada a distância). Contudo, devido à pandemia da Covid-19, as aulas foram suspensas em março de 2020, retornando a referida disciplina, de forma remota, apenas em janeiro de 2021, o que impossibilitou uma avaliação da efetividade dos resultados alcançados e que poderia desencadear uma nova atualização das resoluções e do próprio PPC.

É possível apontar algumas recomendações para prever a curricularização da extensão em PPCs a partir desta experiência: compreender o contexto local e regional onde a instituição está inserida e, assim, fomentar parcerias a fim de garantir a oportunidade aos alunos, tanto de atuação com bolsa quanto como voluntário; mapear as áreas de atuação do corpo docente, avaliar e monitorar o PPC continuamente para acompanhar a oferta extensionista; bem como engajar professores e alunos nesta vertente de contribuição ao enfrentamento das questões que envolvem a sociedade brasileira.

\section{Referências}

BRASIL. Ministério da Educação/Conselho Nacional de Educação (2018) "Resolução No 7/2018". Estabelece as Diretrizes para a Extensão na Educação Superior Brasileira e regimenta o disposto na Meta 12.7 da Lei no 13.005/2014. Brasília-DF.

Cunha, M. X. C. e Souza-Júnior, M. F. (2007) “Análise dos Resultados da Aplicação de Projetos Interdisciplinares em um Curso de Tecnologia sob a Perspectiva dos Alunos". In: Anais do XV Workshop sobre Educação em Computação - WEI, Rio de Janeiro.

Frutuoso, T. P. (2020) “O Processo de Curricularização da Extensão nos Cursos de Graduação do Instituto Federal de Santa Catarina - IFSC”, Dissertação (Mestrado Profissional em Educação Profissional e Tecnológica em Rede Nacional - PROFEPT) - Departamento de Educação à Distância - IFSC. 162 p. Florianópolis.

Imperatore, S. L. B., Pedde, V. e Imperatore, J. L. R. (2015) “Curricularizar a Extensão ou Extensionalizar o Currículo? Aportes Teóricos e Práticas de Integração Curricular da Extensão Ante a Estratégia 12.7 do PNE”. In: XV Colóquio Internacional de Gestão Universitária. Anais. Mar del Plata.

Mello, C. M., Almeida-Neto, J. R. M., Petrillo, R. P. (2020) "Curricularização da Extensão Universitária", 1a ed., Editora Freitas Bastos: Rio de Janeiro-RJ.

Serva, F. M. (2020) "A Extensão Universitária e sua Curricularização". Editora Lumen Juris: Rio de Janeiro-RJ.

Steigleder, L., Zucchetti, D. e Martins, R. (2019) “Trajetória para Curricularização da Extensão Universitária: Contribuições do Fórum Nacional de Extensão das Universidades Comunitárias - FOREXT e a Definição de Diretrizes Nacionais", Revista Brasileira de Extensão Universitária - RBEU, v. 10, n. 3, p. 167-174. 